\title{
Pediatric ventricular assist devices: current challenges and future prospects
}

\author{
This article was published in the following Dove Press journal: \\ Vascular Health and Risk Management \\ 15 May 2017 \\ Number of times this article has been viewed
}

\author{
Sarah Burki ${ }^{1,2}$ \\ Iki Adachi ${ }^{1,2}$ \\ 'Division of Congenital Heart \\ Surgery, Texas Children's Hospital, \\ ${ }^{2}$ Department of Surgery and \\ Pediatrics, Baylor College of Medicine, \\ Houston, TX, USA
}

\begin{abstract}
The field of mechanical circulatory support has made great strides in the preceding 2 decades. Although pediatric mechanical circulatory support has lagged behind that of adults, the gap between them is expected to close soon. The only device currently approved by the US Food and Drug Administration for use in children is the Berlin Heart EXCOR ventricular assist device (VAD). The prospective Berlin Heart Investigational Device Exemption Trial demonstrated good outcomes, such as bridge to transplantation or recovery, in $\sim 90 \%$ of children supported with this device. However, a high incidence of hemorrhagic and thrombotic complications was also noted. As a result, pediatric centers have just started implanting adult intracorporeal continuous-flow devices in children. This paradigm shift has opened a new era in pediatric mechanical circulatory support. Whereas children on VAD were previously managed exclusively in hospital, therapeutic options such as outpatient management and even destination therapy have been becoming a reality. With continued miniaturization and technological refinements, devices currently in development will broaden the range of options available to children. The HeartMate 3 and HeartWare MVAD are two such compact VADs, which are anticipated to have great potential for pediatric use. Additionally, a pediatric-specific continuous-flow VAD, the newly redesigned Jarvik Infant 2015, is currently undergoing preclinical testing and is expected to undergo a randomized clinical trial in the near future. This review aims to discuss the challenges posed by the use of intracorporeal adult continuous-flow devices in children, as well as to provide our perspective on the future prospects of the field of pediatric VADs.
\end{abstract}

Keywords: children, mechanical circulatory support, MCS, single ventricle, SV, chronic graft dysfunction, anticoagulation, miniaturization

\section{Introduction}

The advent of mechanical circulatory support has had a significant impact on the management of heart failure. In particular, adult mechanical circulatory support has rapidly evolved over the past 2 decades. Continued improvements in ventricular assist device (VAD) technology, as well as clinical management, have produced superior outcomes. The introduction of implantable continuous-flow devices with favorable complication profiles, such as the HeartMate II (St. Jude Medical, Inc., St Paul, MN, USA; Figure 1) and HeartWare HVAD (HeartWare, Inc., Framingham, MA, USA; Figure 2), has led to adult physicians favoring VAD support over escalation of medical therapy. As a result, VAD therapy is fast becoming the standard of care for intractable heart failure. Indeed, VAD support may become the primary alternative to heart transplantation in the future. ${ }^{1,2}$

In contrast, despite being a critically unmet need, the development of pediatric mechanical circulatory support continues to lag behind that of adult VADs. Although rea-
Correspondence: Iki Adachi

Department of Congenital Heart Surgery,

Texas Children's Hospital, 662I Fannin

Street, Houston 77005, TX, USA

Tel + I 8328261929

Email iadachi@bcm.edu 


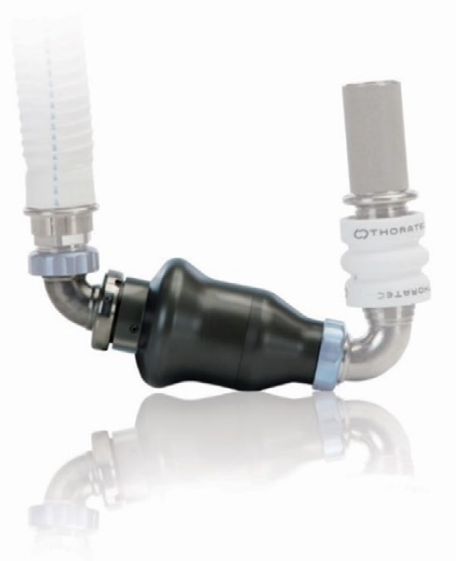

Figure I HeartMate II ${ }^{\mathrm{TM}}$ Left Ventricular Assist Device (LVAD).

Note: HeartMate II, HeartMate 3 and St. Jude Medical are trademarks of St. Jude Medical, Inc. or its related companies. Reproduced with permission of St. Jude Medical, @2016. All rights reserved.

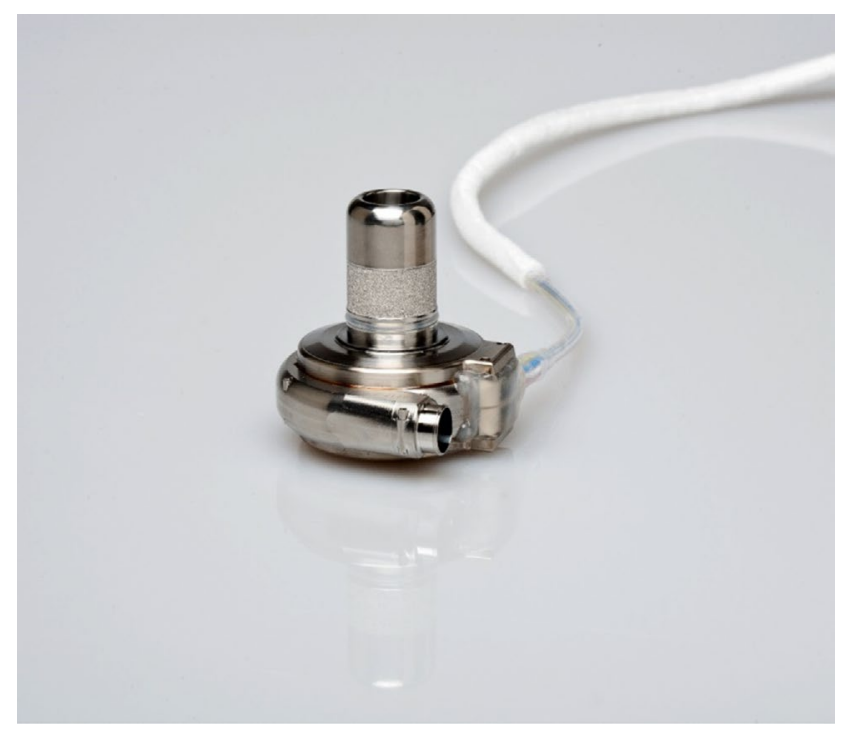

Figure 2 HeartWare ${ }^{\circledR}$ HVAD.

Note: Reproduced with permission from HeartWare ${ }^{\circledR}$, Inc.

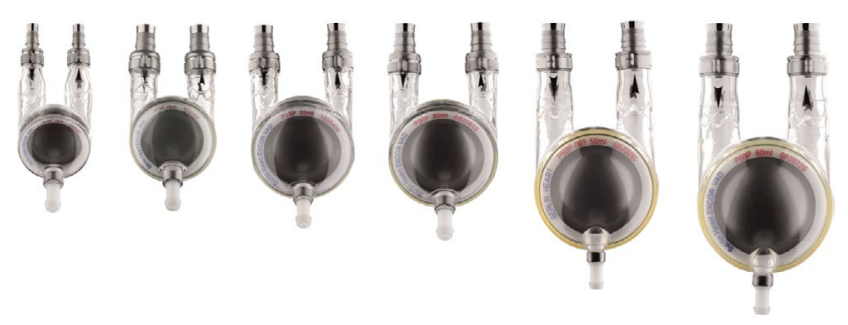

Figure 3 Berlin Heart EXCOR VAD.

Note: Reproduced with permission from Berlin Heart, Inc.

Abbreviation: VAD, ventricular assist device.

sons for this are multifactorial, certain elements, such as patient heterogeneity, smaller consumer numbers, and regulatory challenges, may have disincentivized the development of pediatric devices. ${ }^{3,4}$ The number of children awaiting transplantation is steadily rising ${ }^{5}$ in the setting of static supply of pediatric donor hearts numbering $~ 500$ per annum worldwide. ${ }^{6}$ Improved surgical palliation has allowed an increased proportion of young children with complex congenital heart diseases to survive longer; in many cases, the palliated heart ultimately fails, culminating in the need for transplantation. Pediatric patients awaiting heart transplantation carry the highest waitlist mortality risk of all solid organs. ${ }^{7}$ The ensuing rise in the proportion of sicker children with end-stage heart failure has reinvigorated interest in pediatric mechanical circulatory support. Through this article, the authors aim to present an overview of current challenges facing the realm of pediatric VADs, as well as its future prospects.

\section{Current challenges Challenges in patient selection}

In principle, VAD therapy should be considered when presented with a child with end-stage heart failure in whom medical therapy is failing. However, in order to achieve the best possible outcomes, it is imperative to discern the subset of patients who are poor candidates for VAD support. Selected examples of challenging populations are described subsequently.

\section{Small infants}

Lying at one extreme in the spectrum in pediatric VAD candidates, small infants $(<5 \mathrm{~kg})$ comprise a cohort that presents a unique set of challenges. In a multicenter study, Almond et al ${ }^{8}$ reviewed outcomes of 204 children implanted with the Berlin EXCOR VAD (Berlin Heart, Inc., The Woodlands, TX, USA; Figure 3) at 47 centers between 2007 and 2010. Notably, they found that approximately two thirds of patients weighing $<5 \mathrm{~kg}$ died while on Berlin EXCOR support. ${ }^{8}$ Factors implicated in contributing to such poor outcomes include underlying etiology and potential patient-device size mismatch. In conventional left ventricular assist device (LVAD) physiology, the pump rate is determined by cardiac output from the native right ventricle. In a very small child, therefore, a pump rate may become too low even with the smallest $(10 \mathrm{~mL})$ pump, which is a recognized risk factor for pump thrombosis. For example, if a $3 \mathrm{~kg}$ baby has a cardiac output of $150 \mathrm{~mL} / \mathrm{kg} / \mathrm{min}$, the pump rate will be 45 beats $/ \mathrm{min}(150 \mathrm{~mL} / \mathrm{kg} / \mathrm{min} \times 3 \mathrm{~kg}$ divided by $10 \mathrm{~mL})$ assuming the pump to be fully filled and fully ejected without significant aortic insufficiency. In order to run a pump at a reasonably high rate (ie, 70 beats/min or 80 beats $/ \mathrm{min}$ ), addition of a right ventricular assist device (RVAD) may be necessary in small infants to maintain cardiac output. That said, another study examining 204 Berlin EXCOR VAD implantations in North America between 2007 and 2010 has suggested that 
some children undergoing durable BiVAD support might have done better with LVADs alone. ${ }^{9}$ To mitigate the risk of pump thrombosis, the use of a centrifugal pump, such as PediMag (St. Jude Medical, Inc.) and Rotaflow (Maquet Cardiovascular LLC, Wayne, NJ, USA), may be considered instead of the Berlin EXCOR pulsatile pump; ${ }^{10}$ the efficacy of this approach in small children has not been well studied to date.

Undoubtedly, there is a definitive need for other methods to support the failing heart in this high-risk subset of patients. A potential alternative is pulmonary artery banding (PAB). Schranz et $\mathrm{a}^{11}$ reported their experience with employing this strategy in 12 patients (ten infants and two toddlers) with dilated cardiomyopathy referred for heart transplantation. The authors described an improvement in left ventricular (LV) function by echocardiographic measures (improved LV ejection fraction, decreased LV cavitary volume, and mitral regurgitation), as well as reduced serum brain natriuretic peptide. There were two deaths, and ten patients remained delisted at a mean follow-up of 2 years. The exact reason why PAB improves hemodynamics in children with dilated cardiomyopathy is not well understood. It has been suggested that leftward shift of the interventricular septum by increasing right ventricular afterload may diminish mitral regurgitation, which could improve overall cardiac output. This theory sounds plausible but is not necessarily consistent with our experience. ${ }^{12}$ In a 6-week-old infant (weight, $4 \mathrm{~kg}$ ) with dilated cardiomyopathy in impending need of a VAD, we observed significant hemodynamic improvement with $\mathrm{PAB}$ even with minimal change in septal configuration and mitral regurgitation. For a better understanding of PAB physiology, we monitor pressures of all four cardiac chambers during PAB placement, namely both atria and right ventricle directly and LV (using the arterial line pressure as a surrogate). With gradual tightening of the band, we observed a reduction in left atrial pressure, whereas right atrial pressure changed very little. Although more studies are necessary to confirm this hypothesis, it seems that PAB, in the setting of dilated cardiomyopathy, facilitates a redistribution of hemodynamic stresses exerted by the failing LV to a relatively preserved right ventricle. In selected patients, PAB may reportedly induce cardiac recovery ${ }^{11}$ or may serve as a temporizing measure until a suitable organ becomes available for heart transplantation. Even if the patient deteriorates after PAB placement, the possibility of delaying VAD implantation can be beneficial if somatic growth is achieved on PAB, as VAD outcomes are significantly better in patients weighing $>5 \mathrm{~kg}$ (25\% mortality) compared with those weighing $<5 \mathrm{~kg}$ (64\% mortality), as described in a study by Conway et al. ${ }^{13}$ This significant difference in mortality, however, must be interpreted with caution since the proportion of congenital heart disease was significantly higher in smaller children. In this study, congenital heart disease was identified as an independent risk factor for mortality by a multivariate analysis. ${ }^{13}$ PAB may also condition the RV, which would be favorable for LVAD physiology. ${ }^{12}$

\section{Single-ventricle congenital heart disease}

The decision to provide VAD support in patients with complex single-ventricle physiology warrants careful consideration. In reviewing the outcomes of Berlin EXCOR VAD in the single-ventricle cohort during the Food and Drug Administration Investigational Device Exemption trial, Weinstein et $\mathrm{al}^{14}$ found that survival was significantly worse compared with biventricular physiology ( $42 \%$ vs $73 \%$ ). These data certainly highlight the challenging nature of VAD support in this patient population. A striking finding in their study was the dramatic difference in survival depending on the stage of singleventricle palliation at which the Berlin Heart EXCOR VAD was implanted. Patients after Stage I palliation had extremely poor outcomes (11\% survival), whereas those after Stage II and Stage III did significantly better, with survival reaching $60 \%$. Survival rates with VAD support for Stage II (58\%) and Stage III $(60 \%)$ are still better than previously reported outcomes for ECMO support in single-ventricle physiology (Stage II $[41 \%]^{15}$ and Stage III $[35 \%]^{16}$ ). The type of VAD used for single-ventricle physiology may also have an important clinical impact on outcome. Horne et $\mathrm{al}^{17}$ have described the superiority of continuous-flow VAD over pulsatile VAD. The fact that pulsatile VAD decompresses the failing systemic ventricle only during pump diastole could be deleterious to pulmonary circulation that lacks a pumping chamber (ie, subpulmonary ventricle). There have been several reports describing successful use of an implantable continuous-flow VAD in a failing Fontan circulation (ie, Stage III). ${ }^{18-20}$ Fontan circulations can fail for multiple reasons, including systolic or diastolic dysfunction of the heart, elevated pulmonary vascular resistance, or a combination of these. ${ }^{21}$ In contrast, the use of an implantable continuous-flow VAD in failing Glenn circulation (ie, Stage II) is severely limited, likely due to the smaller size of the patients in this group. To our knowledge, the report we have published recently is the only such case in reported literature. ${ }^{22}$ With ongoing miniaturization of devices, nonetheless, implantable continuous-flow VAD will soon become the mainstay of VAD support for failing Glenn physiology.

\section{Chronic graft dysfunction}

Three decades have passed since pediatric heart transplantation became a clinical reality. ${ }^{23}$ In present days, many of previous 
transplant recipients, now older children, adolescents, and young adults, return with medically resistant chronic graft dysfunction. This represents a particularly difficult population to manage. Some require relisting for heart transplantation; yet, due to relatively preserved systolic function in this subgroup, their listing status is typically not high enough to expect a timely offer. Rather, the underlying process is primarily diastolic dysfunction in the setting of coronary ischemia. As such, preserved systolic cardiac function with nondilated LV cavity creates technical challenges in placing a VAD inflow cannula if attempted. In addition, patients' immunocompromised state increases the risk of infectious complications with VAD support. ${ }^{24}$ The Total Artificial Heart (Syncardia Systems, Inc., Tucson, AZ, USA; Figure 4) presents an alternate option in these circumstances since cardiectomy, as a part of the implantation procedure, permits discontinuation of immunosuppression. Due to size constraints with the existing $70 \mathrm{~mL}$ pump, pediatric patients are unlikely to avail this option. ${ }^{25}$ The development of smaller pumps $(50 \mathrm{~mL})$ may widen its indication to some degree. A clinical trial with the $50 \mathrm{~mL}$ pump in the pediatric population is to begin. ${ }^{26}$

\section{Challenges associated with optimal timing of VAD support}

Determining not only whom but also when to initiate VAD support is also challenging. While waiting too long to initiate VAD support sharply increases the risk of mortality and

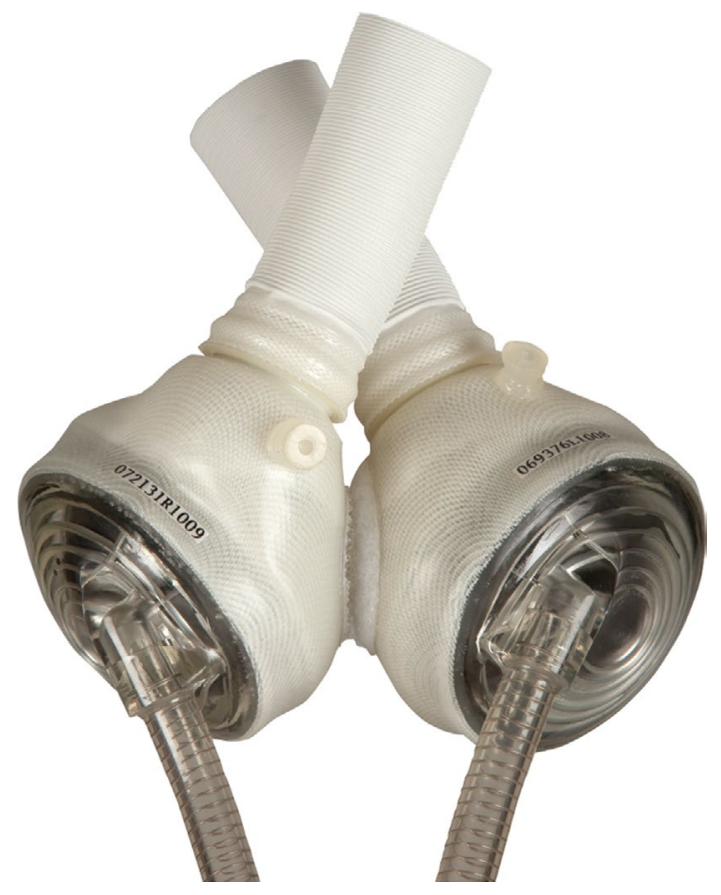

Figure 4 Total artificial heart (Syncardia Systems, Inc.). Note: Figure courtesy of syncardia.com. morbidity, implanting a VAD too early also predisposes the patient to risks of device-related complications. Therefore, ascertaining the optimal timeframe within which to start VAD therapy is crucial to securing good outcomes. In the early days of device evolution, an exceedingly high complication profile of VAD support essentially restricted offering mechanical support to patients who were critically unwell, that is INTERMACS Stage I (critical cardiogenic shock with evidence of end-organ injury). ${ }^{27}$ Accumulated VAD experience has demonstrated poor outcomes with this approach. ${ }^{1}$ Subsequently, particularly in the adult patient population, the paradigm has shifted in favor of instituting VAD support earlier, that is, when the patient is more stable, with a significant resultant improvement in morbidity and mortality. ${ }^{28}$ Practices in pediatric VAD management are often extrapolated from observed trends within existing adult data. However, the aforementioned trend of earlier VAD implantation in adults has not yet been adopted in pediatric settings. Pediatric physicians traditionally err on the conservative side with respect to initiating VAD support. To date, most children with heart failure undergo VAD placement at INTERMACS Stage I or Stage II, especially small children who can be supported only with a pulsatile VAD. In the entire North American experience with the EXCOR, $>50 \%$ of patients were at INTERMACS Stage I and $40 \%$ were on ECMO support at the time of VAD implantation. ${ }^{6}$ Additionally, there has been a clear trend toward longer duration of VAD support in the recent era. ${ }^{29}$ Considering the fact that risks of device-related complications, such as embolic stroke, increase proportionately with the length of support duration, it stands to reason that the burden of such risks may increase further. The window for instituting VAD support in children with rapidly deteriorating hemodynamics is small, leaving little room for error; it is thus essential to strike a balance between reaping the intended benefits of VAD support and avoiding exposure to risk of complications prematurely, if best outcomes are to be ensured.

\section{Challenges with influencing risk profiles of existing devices \\ Continuous-flow VAD in adolescents}

As described earlier, in order to take advantage of predictable complication profiles while simultaneously circumventing the risk of morbidity associated with pulsatile devices, pediatric centers are starting to favor implanting adult continuous-flow devices in children. Continuous-flow devices are anticipated to be increasingly used in the pediatric population, driven by theoretically better complication profiles and the potential for 
home discharge. Although it is premature to conclude that the use of continuous-flow VADs in children is a reasonably safe option, preliminary experiences are encouraging.

The most widely used implantable continuous-flow devices in the adult population is the HeartMate II. Its popularity is driven by a lower incidence of thromboembolic complications compared with previous VADs. ${ }^{30}$ According to the Seventh INTERMACS report, the rate of strokes in the first year after continuous-flow VAD implant in adults in the recent era (2012-2014) stands at 1.61 events per 100 patient months of support. ${ }^{28}$ The HeartMate II presents an excellent option for older children and adolescents with a body surface area of $>1.3 \mathrm{~m}^{2}$. Reported outcomes with the device in appropriately selected patients are good, with $>90 \%$ of children implanted with a HeartMate II surviving to transplant, explanted for recovery, or continuing on support at 6 months follow-up. ${ }^{31}$ The use of this device has largely negated the need for Berlin EXCOR $50 \mathrm{~mL}$ and $60 \mathrm{~mL}$ pumps in adolescents. Compact continuous-flow VADs, such as the HVAD, may be implanted in both right and left ventricles to provide hemodynamic support in appropriately sized adolescents with biventricular failure. ${ }^{32}$ From a viewpoint of logistics surrounding pediatric VAD programs, the most significant impact the HeartMate II has had is that pediatric centers have learned how to manage their patients on VAD support on an outpatient basis. In the previous era where the pulsatile pump was the sole option for children, virtually all the patients with VAD support were managed as in-patients. In a recent multi-institutional study, we have demonstrated the feasibility of discharging majority of children on HVAD support, who may then go on to resume regular activities. ${ }^{33}$ However, recent studies (including the PediMACS registry data) show that about half of the patients supported by continuous-flow VADs are still managed in hospital. ${ }^{34-36}$ As the experience with continuous-flow VAD in children advances, the home discharge rate will steadily increase. At our institution, nearly all children implanted with continuous-flow VADs are discharged home. The fact that the pediatric community has learned what is prerequisite to discharging children with ongoing VAD support (ie, education of primary caregivers and school teachers, etc) has made it possible to move the pediatric VAD programs to the next stage where a miniaturized continuous-flow VAD is offered even to small children.

\section{Continuous-flow VAD in small children}

The emergence of a smaller continuous-flow device further accelerated the trend of favoring continuous-flow VAD in children. The HVAD is now gaining wider attention from pediatric centers worldwide due to its compact design. Debate is ongoing with respect to how young and how small an HVAD recipient can be. Anecdotal experience with the HVAD suggests that children with a body surface area as low as $0.6 \mathrm{~m}^{2}$ may be candidates for HVAD support. ${ }^{35}$ This is consistent with our experience. The smallest patient in our series was a 4-year-old boy weighing $13 \mathrm{~kg}$ with a body surface area of $0.6 \mathrm{~m}^{2}$ at HVAD implantation. He has been supported well (>600 days of ongoing support) without any neurologic events. These anecdotal experiences clearly demonstrate the potential feasibility of continuous-flow VAD support even in small children. . $^{2,30,31,35,37}$

Care must be taken, however, when applying adult devices in smaller children since this will, by definition, inevitably result in patient-device size mismatch. For example, an inflow cannula may be too large for a child's intraventricular cavitary volume. When adult-sized pulsatile pumps were used in children, the most significant risk factor for poor outcome was the size of patients; ${ }^{38}$ the smaller the child, the worse the survival. In other words, the degree of patient-device size mismatch has a direct impact on outcome. Having realized the difference between pulsatile and continuous-flow devices, however, it would be still prudent to assume that size mismatch remains a risk in the current era of the use of continuous-flow VAD.

\section{Surgical modifications to mitigate patient-device size mismatch}

Considering the inevitable dilemma of patient-device size mismatch, avenues to improve outcomes must be found until pediatric-specific, age-appropriate devices become available. We have found potential areas of improvement in making the HVAD work efficiently in children. Foremost, the standard implantation technique that has proven effective in the adult population may not be the best option for pediatric patients.

In our opinion, the most critical aspect is the angle of the inflow cannula relative to the interventricular septum. In this regard, the standard technique, so-called "intrapericardial placement", is suboptimal. A concern with the standard intrapericardial placement is that the pump inflow typically lies in a horizontal plane (ie, perpendicular to the interventricular septum). ${ }^{39,40}$ One of the most important lessons learned from the large experience ( $>20,000$ implants worldwide) with the HeartMate II is that such a perpendicular orientation of the inflow cannula relative to the septum may predispose to pump thrombosis or suction events. ${ }^{41}$ Although one can argue that HVAD is not exactly the same as the HeartMate II, the fundamental principle of the inflow cannula configuration should be the same: the inflow cannula needs to be parallel, rather than 
perpendicular, to the interventricular septum. The concern for inflow angle with the standard technique was first raised by the team at Texas Heart Institute, led by $\mathrm{OH}$ Frazier. His group places the inflow cannula through the diaphragmatic surface of the LV, rather than the apex. ${ }^{39}$ While this approach is an attractive option in adults who have comparatively large ventricular cavities, it may be less than ideal in those with smaller hearts. With the posterior descending coronary artery running in close proximity to the proposed implantation site, myocardial perfusion may be jeopardized by the occlusive effects of the sewing ring. Our preference is to use the LV apex as an insertion site, consistent with the standard approach. However, we place the pump in a pocket created by dividing the left hemidiaphragm. ${ }^{40}$ The cardiac apex is thus oriented more caudomedially, aligning the inflow cannula in a vertical orientation (ie, parallel to the interventricular septum). The key concept of our approach is that by affixing the pump housing within the pocket, the surgeon can determine the angle of the inflow cannula, rather than letting the pump "free-float" within the pericardial sac. Although there is no contemporary data to prove the superiority of this approach over the conventional one in small children, we believe the relationship of the inflow cannula relative to the interventricular septum is important. A caveat remains in that the smaller the LV, the lower the tolerance for technical imperfections. Miera et $\mathrm{a}^{35}$ recently published their experience with the use of HVAD in small children with a body surface area of $\leq 1.0 \mathrm{~m}^{2}$. In this multicenter retrospective study, four patients (33\%) out of 12 , excluding one who died early postoperatively, experienced pump thrombosis. In our experience of 19 HVAD implants at Texas Children's Hospital, we have not had any pump thrombosis events despite a lower target international normalized ratio (INR) (2.0-2.5) compared with relatively high target ( $>2.5$ up to 3.5 ) in the multicenter study. Further discussion is necessary to clarify what would be the best implantation technique for small children.

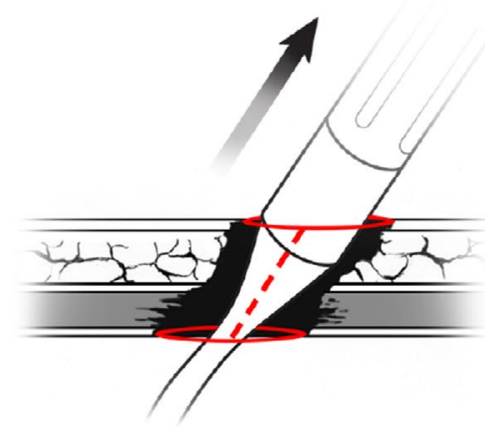

A driveline is the Achilles' heel of implantable VADs. In our opinion, special care also must be taken when tunneling the driveline through a comparatively less developed abdominal wall in sick children. Goldstein et $\mathrm{al}^{42}$ reported interesting findings using the INTERMACS registry. The authors demonstrated that the younger the patient (among the adult age group), the higher the risk of driveline infection. ${ }^{42}$ Due to its retrospective nature using registry data, reasons behind this finding are unclear. One may assume that younger patients are more active, and therefore the driveline exit site is subjected to a greater degree of stress, an identified risk factor for developing driveline site infections. In our experience, pediatric patients are prone to driveline site issues due to vigorous physical activity, as can be expected in children, and inattentiveness to the driveline. It stands to reason, then, that the risk of developing this complication is reportedly high in children, with up to $80 \%$ of VAD-specific infections involving the driveline. ${ }^{43}$ The problem with the standard tunneling technique for the HVAD driveline is that the integrity of the abdominal muscle layer, which is the primary supporting mechanism of the driveline, is destroyed by passing the large connector part (12 $\mathrm{mm}$ in diameter; triple the size of the cable; Figure 5). Surgical modifications such as ours that maintain the abdominal wall integrity may solve issues related to driveline in active children. ${ }^{44}$

\section{Anticoagulation strategies}

Strategies surrounding anticoagulation and its surveillance vary considerably between institutions. Durable VAD support requires chronic forms of anticoagulation, ie, warfarin and antiplatelet agents, often requiring a heparin bridge. As desirable as it may be, achieving optimal anticoagulation in children on VAD support is challenging on account of certain developmental differences in hemostasis (eg, pharmacokinetics/pharmacodynamics of anticoagulants, decreased thrombin generation and fibrinolytic capacity, and

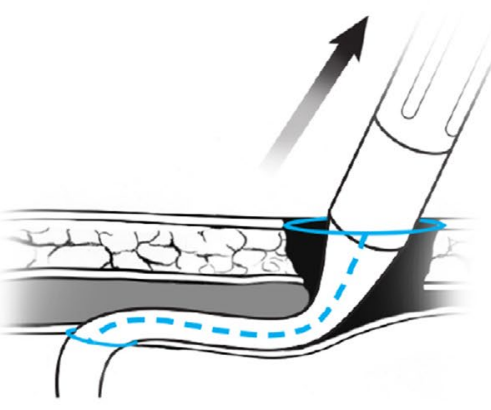

(C) 2014 Texas Children's Hospital 
increased inhibitory capacity).$^{45}$ As a result, children on VADs may either be overanticoagulated (manifested as hemorrhagic complications) or underanticoagulated (manifested as thrombotic complications). Anticoagulation is also impacted by the type of VAD selected: balancing anticoagulation on the pulsatile Berlin EXCOR VAD is more challenging due to its inherent tendency for fibrin/thrombus formation. Although the standard anticoagulation regimen for the Berlin EXCOR VAD (known as the Edmonton protocol) calls for low-molecular weight heparin in infants, our institutional preference is to administer warfarin to all age groups. With this particular device, the narrow gap between two related complications, namely hemorrhage and thrombosis, often results in the clinician tolerating over- or underanticoagulation, depending on the patient's current clinical state. Presence of concomitant systemic inflammation, often associated with hypercoagulability, further complicates matters by requiring extremely high doses of anticoagulants in order to attain therapeutic levels. As such, it is our policy that if anticoagulation cannot be achieved without excessive anticoagulation, the clinician may need to accept subtherapeutic anticoagulation while maintaining a very low threshold to exchange the pump for fibrin deposition/thrombosis. This "permissive under-anticoagulation" strategy is particularly important in the early postoperative period when the risk of bleeding exceeds the risk of thrombotic complications. ${ }^{46}$

\section{Future prospects}

Driven by the continued demand for device miniaturization, small-sized adult devices are currently in development, and may pave the way for greater adoption in pediatric cohort. The wave of implantable continuous-flow VADs may finally reach small children.

Compared to its larger predecessor, the HeartMate 3 (St. Jude Medical, Inc., Figure 6) is a device on the horizon, which has potential for use in children. At full range of operation, it is able to provide flows between $2.5 \mathrm{~L} / \mathrm{min}$ and $10 \mathrm{~L} / \mathrm{min}$, as well as an artificial pulse by alternating the pump rotor speed once every other second. In October 2015, the device received the Conformité Européenne Mark approval. The trial enrolled 50 patients in six European hospitals. Six-month survival was $92 \%$. There were no pump thrombosis events, and adverse event rates were lower than or consistent with expectations for severely ill and complex patients requiring LVAD support. The MOMENTUM 3 Investigational Device Exemption trial is ongoing in the US. ${ }^{47}$

The MVAD (HeartWare, Inc.; Figure 7) is a device, which is currently undergoing testing. It has a displacement volume of $20 \mathrm{~mL}$ and weighs $<100 \mathrm{~g}$. Its speed ranges from 8,000 rpm

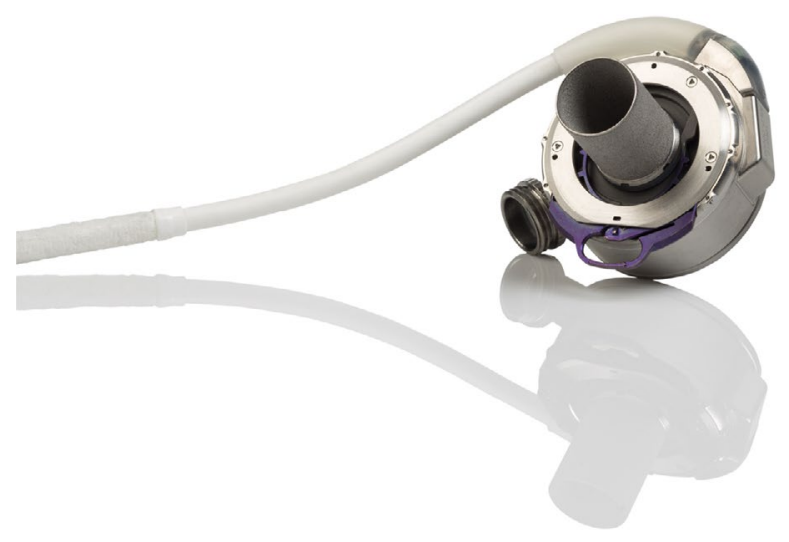

Figure 6 HeartMate $3^{\mathrm{TM}}$ Left Ventricular Assist Device (LVAD). Note: HeartMate II, HeartMate 3 and St. Jude Medical are trademarks of St. Jude Medical, Inc. or its related companies. Reproduced with permission of St. Jude Medical, (2016. All rights reserved.

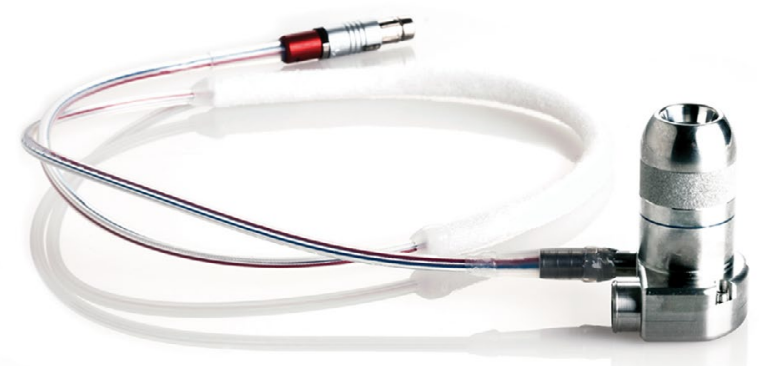

Figure 7 HeartWare ${ }^{\circledR}$ MVAD.

Notes: Caution: Investigational device, exclusively for clinical investigation. Investigational device should be used by qualified investigators only. Reproduced with permission from HeartWare ${ }^{\circledR}$, Inc.

to $18,000 \mathrm{rpm}$ and is capable of delivering blood flow between $1 \mathrm{~L} / \mathrm{min}$ and $7 \mathrm{~L} / \mathrm{min}$ at a pressure of $75 \mathrm{mmHg}$. Moreover, unique features such as an adjustable inflow angle relative to the sewing ring $\left( \pm 10^{\circ}\right)$ and an adjustable inflow cannula depth allow customizable configuration to ensure a good fit. The Conformité Européenne Mark trial commenced in July 2015 with first implants performed in the UK and Austria. Simultaneously, HeartWare had applied to the Food and Drug Administration for an Investigational Device Exemption to commence clinical trials in the US. ${ }^{48}$ Given the size of the device, the MVAD may have the potential to completely change the outlook of pediatric VAD support.

Finally, the Jarvik Infant (Jarvik Heart, Inc., New York, NY, USA; Figure 8) is an implantable continuous-flow VAD specifically designed for small children. It had previously experienced setbacks due to hemolysis, resulting in disapproval of Investigational Device Exemption applications. Recently, though, it has undergone significant design overhaul. In the latest iteration, the Jarvik Infant 2015, the size of inflow cannula has increased from $11 \mathrm{~mm}$ to $15 \mathrm{~mm}$. This long-awaited 


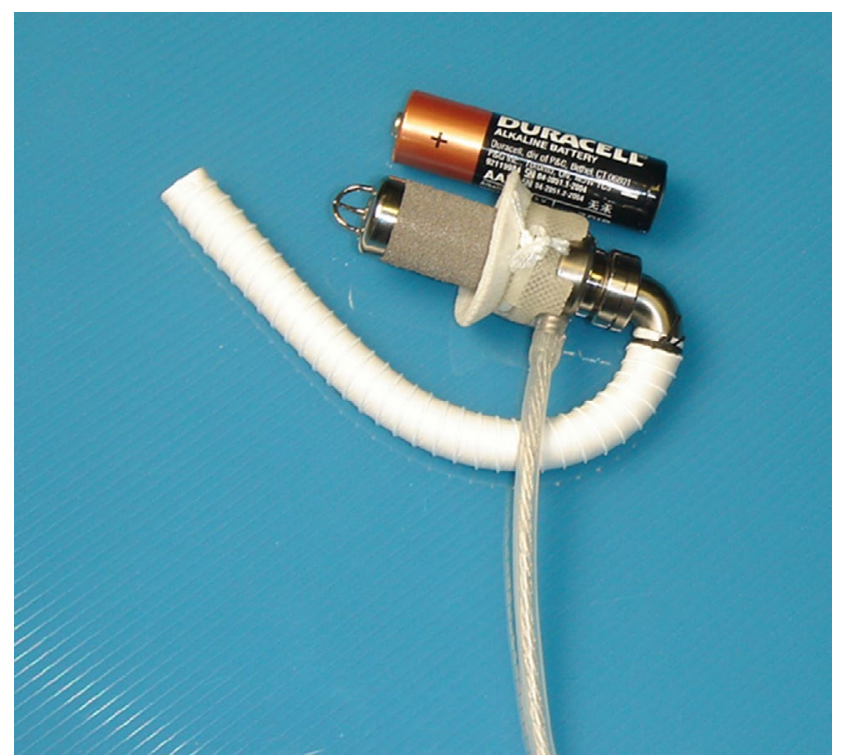

Figure 8 Jarvik Infant VAD.

Note: Reproduced with permission from Jarvik Heart, Inc.

Abbreviation: $\mathrm{VAD}$, ventricular assist device.

device is currently undergoing preclinical testing as collaboration between our center and the Texas Heart Institute. Once successfully completed, this device will be evaluated in the PumpKIN trial (pumps for kids, infants, and neonates) funded by the National Heart, Lung, and Blood Institute, a subsidiary of the National Institutes of Health. This trial is intended to be a two-arm prospective randomized trial where patients will be randomly allocated to receive either the Berlin EXCOR or the Jarvik Infant 2015 device, with each group consisting of 44 patients. ${ }^{49}$ This trial may open the era of the use of implantable continuous-flow VADs in small children.

\section{Conclusion}

To summarize, development of pediatric VADs has not kept pace with adult devices, yet this gap is expected to soon close as overall experience with VADs evolves and the number of potential pediatric candidates for VAD support rises. The contemporary field of pediatric VAD therapy poses many challenges including determining which candidate would derive most benefit from VAD support and selecting the best device for the patient considering their individual clinical circumstances and inherent device complication profiles. Owing to their favorable complication profiles, continuousflow VADs previously reserved for adults are now being used more frequently in children, predisposing to patient-device size mismatch. The scope of employing continuous-flow VADs in children has widened as solutions to mitigating consequences of patient-device size mismatch are found. Future prospects of pediatric VADs are certainly encouraging: with the continued demand for technological adaptations, such as device miniaturization, it is anticipated that VAD therapy will play a more prominent role in successfully managing children with end-stage heart failure.

\section{Disclosure}

Iki Adachi, MD, serves as a consultant and proctor for the Berlin Heart Inc. and the HeartWare Inc. Dr Adachi receives a salary support for his role as a consultant with the New England Research Institute related to the PumpKIN trial. The authors report no other conflicts of interest in this work.

\section{References}

1. Kirklin JK, Naftel DC, Kormos RL, et al. Fifth INTERMACS annual report: risk factor analysis from more than 6,000 mechanical circulatory support patients. J Heart Lung Transplant. 2013;32(2):141-156.

2. Birks EJ. The comparative use of ventricular assist devices: differences between Europe and the United States. Tex Heart Inst J. 2010; 37(5):565-567.

3. Baldwin JT, Borovetz HS, Duncan BW, Gartner MJ, Jarvik RK, Weiss WJ. The national heart, lung, and blood institute pediatric circulatory support program: a summary of the 5-year experience. Circulation. 2011;123(11):1233-1240.

4. Almond CS, Chen EA, Berman MR, et al. High-risk medical devices, children and the FDA: regulatory challenges facing pediatric mechanical circulatory support devices. ASAIO J. 2007;53(1):4-7.

5. Rossano JW, Kim JJ, Decker JA, et al. Prevalence, morbidity, and mortality of heart failure-related hospitalizations in children in the United States: a population-based study. J Card Fail. 2012;18(6):459-470.

6. Dipchand AI, Rossano JW, Edwards LB, et al. The Registry of the International Society for Heart and Lung Transplantation: eighteenth official pediatric heart transplantation report? 2015; Focus theme: early graft failure. J Heart Lung Transplant. 2015;34(10):1233-1243.

7. Almond CS, Thiagarajan RR, Piercey GE, et al. Waiting list mortality among children listed for heart transplantation in the United States. Circulation. 2009;119(5):717-727.

8. Almond CS, Morales DL, Blackstone EH, et al. Berlin heart EXCOR pediatric ventricular assist device for bridge to heart transplantation in US Children. Circulation. 2013;127(16):1702-1711.

9. Zafar F, Jefferies JL, Tjossem CJ, et al. Biventricular Berlin heart EXCOR pediatric use across the United States. Ann Thorac Surg. 2015;99(4):1328-1334.

10. MaatAP, van Thiel RJ, Dalinghaus M, Bogers AJ. Connecting the Centrimag Levitronix pump to Berlin Heart Excor cannulae; a new approach to bridge to bridge. J Heart Lung Transplant. 2008;27(1):112-115.

11. Schranz D, Rupp S, Muller M, et al. Pulmonary artery banding in infants and young children with left ventricular dilated cardiomyopathy: a novel therapeutic strategy before heart transplantation. J Heart Lung Transplant. 2013;32(5):475-481.

12. Goldberg JF, Vesel TP, Jeewa A, Adachi I. Pulmonary artery band reduces left atrial pressure in dilated cardiomyopathy. Ann Thorac Surg. 2015;100(2):e35-e36.

13. Conway J, St. Louis J, Morales DLS, Law S, Tjossem C, Humpl T. Delineating survival outcomes in children $<10 \mathrm{~kg}$ bridged to transplant or recovery with the Berlin heart EXCOR ventricular assist device. JACC Heart Fail. 2015;3(1):70-77.

14. Weinstein S, Bello R, Pizarro C, et al. The use of the Berlin Heart EXCOR in patients with functional single ventricle. J Thorac Cardiovasc Surg. 2014;147(2):697-704; discussion 704-705.

15. Jolley M, Thiagarajan RR, Barrett CS, et al. Extracorporeal membrane oxygenation in patients undergoing superior cavopulmonary anastomosis. J Thorac Cardiovasc Surg. 2014;148(4):1512-1518. 
16. Rood KL, Teele SA, Barrett CS, et al. Extracorporeal membrane oxygenation support after the Fontan operation. J Thorac Cardiovasc Surg. 2011;142(3):504-510.

17. Horne D, Conway J, Rebeyka IM, Buchholz H. Mechanical circulatory support in univentricular hearts: current management. Semin Thorac Cardiovasc Surg Pediatr Card Surg Annu. 2015;18(1):17-24.

18. Morales DL, Adachi I, Heinle JS, Fraser CD Jr. A new era: use of an intracorporeal systemic ventricular assist device to support a patient with a failing Fontan circulation. J Thorac Cardiovasc Surg 2011;142(3):e138-e140.

19. Niebler RA, Ghanayem NS, Shah TK, et al. Use of a HeartWare ventricular assist device in a patient with failed Fontan circulation. Ann Thorac Surg. 2014;97(4):e115-e116.

20. Miera O, Potapov EV, Redlin M, et al. First experiences with the HeartWare ventricular assist system in children. Ann Thorac Surg. 2011; 91(4):1256-1260.

21. VanderPluym C, Urschel S, Buchholz H. Advanced therapies for congenital heart disease: ventricular assist devices and heart transplantation. Can J Cardiol. 2013;29(7):796-802.

22. Adachi I, Jeewa A, Burki S, McKenzie ED, Fraser CD Jr. Outpatient management of a child with bidirectional Glenn shunts supported with implantable continuous-flow ventricular assist device. J Heart Lung Transplant. 2016;35(5):688-690.

23. Chinnock RE, Bailey LL. Heart transplantation for congenital heart disease in the first year of life. Curr Cardiol Rev. 2011;7(2): $72-84$.

24. Adachi I, Guzman-Pruneda FA, Khan MS, McKenzie ED, Fraser CD Jr. Ventricular assist device in children with cardiac graft failure. ASAIOJ. 2015;61(6):729-730

25. Ryan TD, Jefferies JL, Zafar F, Lorts A, Morales DL. The evolving role of the total artificial heart in the management of end-stage congenital heart disease and adolescents. ASAIO J. 2015;61(1):8-14.

26. SynCardia [webpage on the Internet]. FDA Approves Investigational Study for New Smaller SynCardia Total Artificial Heart. Available from: http://www.syncardia.com/2015-multimedia-releases/fda-approvesinvestigational-study-for-smaller-syncardia-total-artificial-heart/ itemid-1750.html. Accessed June 25, 2016.

27. Stevenson LW, Pagani FD, Young JB, et al. INTERMACS profiles of advanced heart failure: the current picture. J Heart Lung Transplant. 2009;28(6):535-541.

28. Kirklin JK, Naftel DC, Pagani FD, et al. Seventh INTERMACS annual report: 15,000 patients and counting. J Heart Lung Transplant. 2015; 34(12):1495-1504.

29. Adachi I, Khan MS, Guzman-Pruneda FA, et al. Evolution and impact of ventricular assist device program on children awaiting heart transplantation. Ann Thorac Surg. 2015;99(2):635-640.

30. Pagani FD, Miller LW, Russell SD, et al; HeartMate II Investigators. Extended mechanical circulatory support with a continuous-flow rotary left ventricular assist device. J Am Coll Cardiol. 2009;54(4) 312-321.

31. Cabrera AG, Sundareswaran KS, Samayoa AX, et al. Outcomes of pediatric patients supported by the HeartMate II left ventricular assist device in the United States. J Heart Lung Transplant. 2013;32(11):1107-1113.

32. Stein ML, Yeh J, Reinhartz O, et al. HeartWare HVAD for biventricular support in children and adolescents: The Stanford experience. ASAIO $J$. Epub 2016 Feb 25.
33. Schweiger M, Vanderpluym C, Jeewa A, et al. Outpatient management of intra-corporeal left ventricular assist device system in children: a multi-center experience. Am J Transplant. 2015;15(2):453-460.

34. Rossano JW, Lorts A, VanderPluym CJ, et al. Outcomes of pediatric patients supported with continuous-flow ventricular assist devices: a report from the Pediatric Interagency Registry for Mechanical Circulatory Support (PediMACS). J Heart Lung Transplant. 2016;35(5):585-590.

35. Miera O, Kirk R, Buchholz H, et al. A multicenter study of the HeartWare HVAD ventricular assist device in small children. J Heart Lung Transplant. 2016;35(5):679-681.

36. Peng E, Kirk R, Wrightson N, et al. An extended role of continuous flow device in pediatric mechanical circulatory support. Ann Thorac Surg. Epub 2016 Apr 26.

37. Padalino MA, Bottio T, Tarzia V, et al. HeartWare ventricular assist device as bridge to transplant in children and adolescents. Artif Organs. 2014;38(5):418-422.

38. Blume ED, Naftel DC, Bastardi HJ, et al; Pediatric Heart Transplant Study Investigators. Outcomes of children bridged to heart transplantation with ventricular assist devices: a multi-institutional study. Circulation. 2006;113(19):2313-2319.

39. Gregoric ID, Cohn WE, Frazier OH. Diaphragmatic implantation of the HeartWare ventricular assist device. J Heart Lung Transplant. 2011;30(4):467-470.

40. Adachi I, Guzman-Pruneda FA, Jeewa A, Fraser CD Jr, Dean McKenzie E. A modified implantation technique of the HeartWare ventricular assist device for pediatric patients. J Heart Lung Transplant. 2015;34(1):134-136.

41. Taghavi S, Ward C, Jayarajan SN, Gaughan J, Wilson LM, Mangi AA. Surgical technique influences HeartMate II left ventricular assist device thrombosis. Ann Thorac Surg. 2013;96(4):1259-1265.

42. Goldstein DJ, Naftel D, Holman W, et al. Continuous-flow devices and percutaneous site infections: clinical outcomes. J Heart Lung Transplant. 2012;31(11):1151-1157.

43. Cabrera AG, Khan MS, Morales DLS, et al. Infectious complications and outcomes in children supported with left ventricular assist devices. J Heart Lung Transplant. 2013;32(5):518-524.

44. Asaki SY, Dean McKenzie E, Elias B, Adachi I. Rectus-sparing technique for driveline insertion of ventricular assist device. Ann Thorac Surg. 2015;100(5):1920-1922.

45. Massicotte MP, Bauman ME, Murray J, Almond CS. Antithrombotic therapy for ventricular assist devices in children: do we really know what to do? J Thromb Haemost. 2015;13(Suppl 1):S343-S350.

46. Byrnes JW, Frazier E, Tang X, et al. Hemorrhage requiring surgical intervention among children on pulsatile ventricular assist device support. Pediatr Transplant. 2014;18(4):385-392.

47. THORATEC [webpage on the Internet]. St. Jude Medical Announces CE Mark Approval for the HeartMate 3 Left Ventricular Assist System. Available from: https://www.thoratec.com/medical-professionals/vadproduct-information/heartmate3/HeartMate3-CE-Mark-Press-Release. pdf. Accessed June 25, 2016.

48. HeartWare [webpage on the Internet]. HeartWare International Announces First Human Implants Of The MVAD ${ }^{\circledR}$ System In CE Mark International Clinical Trial. Available from: http://ir.heartware.com/ phoenix.zhtml?c=187755\&p=irol-newsArticle_print\&ID=2068959 Accessed June 25, 2016.

49. Scheel JN. News from the PumpKIN Patch. ISHLT Links. 2014;6(3).
Vascular Health and Risk Management

\section{Publish your work in this journal}

Vascular Health and Risk Management is an international, peerreviewed journal of therapeutics and risk management, focusing on concise rapid reporting of clinical studies on the processes involved in the maintenance of vascular health; the monitoring, prevention and treatment of vascular disease and its sequelae; and the involvement of
Dovepress

metabolic disorders, particularly diabetes. This journal is indexed on PubMed Central and MedLine. The manuscript management system is completely online and includes a very quick and fair peer-review system, which is all easy to use. Visit http://www.dovepress.com/ testimonials.php to read real quotes from published authors. 